\title{
Bacterial translocation markers in liver cirrhosis
}

\author{
Alexandra Alexopoulou, Danai Agiasotelli, Larisa E. Vasilieva, Spyros P. Dourakis \\ Medical School, National and Kapodistrian University of Athens, Hippokration Hospital, Athens, Greece
}

\section{Abstract}

\section{Introduction}

Bacterial infections are frequent in cirrhosis and represent the most common cause of hospitalization [1,2]. Despite progress in their pathogenesis, prevention and management, bacterial infections still remain a cause of mortality and admission to intensive care units. The European Association for the Study of the Liver (EASL), after a special session in 2013 in Barcelona, reported that the severity and incidence of infections in cirrhosis is higher than in the general population and pointed out the increasing risk of infection by multiresistant bacterial strains [3]. In addition, they highlighted

\footnotetext{
$2^{\text {nd }}$ Department of Internal Medicine, Medical School, National and Kapodistrian University of Athens, "Hippokration" Hospital, Athens, Greece
}

Conflict of Interest: None

Correspondence to: Dr. Alexandra Alexopoulou, MD, $2^{\text {nd }}$ Department of Medicine, "Hippokration" Hospital, Medical School, National and Kapodistrian University of Athens, 114 Vas. Sophias St, Athens, Greece, Tel.: +30 210 7774742, Fax: +30 210 7706871,

e-mail: alexopou@ath.forthnet.gr

Received 12 March 2017; accepted 19 June 2017; published online 25 July 2017

DOI: https://doi.org/10.20524/aog.2017.0178 the importance of the empirical use of antibiotics in both community-acquired and nosocomial or healthcare-associated infections.

The most common infections in patients with cirrhosis are spontaneous bacterial peritonitis (SBP), urinary tract infection, pneumonia, infections of soft tissues, and spontaneous bacteremia [4]. Factors associated with a high incidence of infection are liver failure, variceal bleeding, decreased albumin concentration in ascitic fluid, a history of SBP and previous hospitalization $[5,6]$. Given the high frequency of Gram-negative infections, it seems that most infections in patients with liver cirrhosis are of enteric origin and that the pathogenetic mechanism explaining the development of SBP is the passage of viable bacteria from the intestinal lumen through the intestinal wall to the mesenteric lymph nodes or other sites. This phenomenon was first described in 1979 and is called bacterial translocation (BT) [7].

\section{BT}

BT is defined as the migration of live microorganisms or bacterial endotoxins (e.g. bacterial lipopolysaccharide [LPS], peptidoglycan, lipopeptide) from the intestinal lumen to the mesenteric lymph nodes and extraintestinal sites $[7,8]$. The most common bacteria involved in BT are derived from the 
family of Enterobacteriaceae (Escherichia coli [E. coli], Klebsiella $s p p$, etc.), Enterococci and Streptococci spp., while species of anaerobic microorganisms are rarely responsible for BT $[9,10]$. It has been shown that BT is related to the stage of liver failure and is more prominent in advanced liver disease as estimated by the Child-Pugh score [11]. Moreover, it is more frequent in experimental models with ascites than in those without [12].

Our knowledge of the pathogenesis of BT is based on studies in experimental animals, in which BT is defined as positive bacterial culture of surgically removed mesenteric lymph nodes. However, in humans the difficulty of surgical access to mesenteric lymph nodes means that only a few studies have been reported [13]. The mechanisms related to the pathogenesis of BT in cirrhosis vary and include bacterial overgrowth in the small intestine, disorders of intestinal permeability and impairment of the immune system (Fig. 1) [14-17].

\section{Bacterial overgrowth in the small intestine}

This is a syndrome characterized by an increased number and/or abnormal type of bacteria in the small intestine [14].
The optimal method for diagnosis is quantitative culture of jejunal aspirates $[18,19]$. Hydrogen and methane breath tests $[20,21]$ have also been used as noninvasive methods, but they are characterized by low sensitivity [18]. Slow intestinal transit due to decreased bowel motility, low secretion of gastric acid and bile acid, and local intestinal immunological defects are factors related to bacterial overgrowth (Fig. 1) [14]. Increased catecholamine activity, high production of nitric oxide (NO) inducing vasodilatation, and portal hypertension causing hyperemia of submucous capillaries and veins may further facilitate bacterial overgrowth [22-24].

\section{Increased intestinal permeability}

Structural and functional changes in the intestinal mucosa increase its permeability and result in BT (Fig. 1). The intestinal barrier includes secretory and natural defense mechanisms against microorganisms. Intestinal mucosa and intercellular junctions among epithelial cells form a layer that allows selective passage of the toxins and bacterial products [14]. Mucus produced by intestinal epithelial cells forms a thick

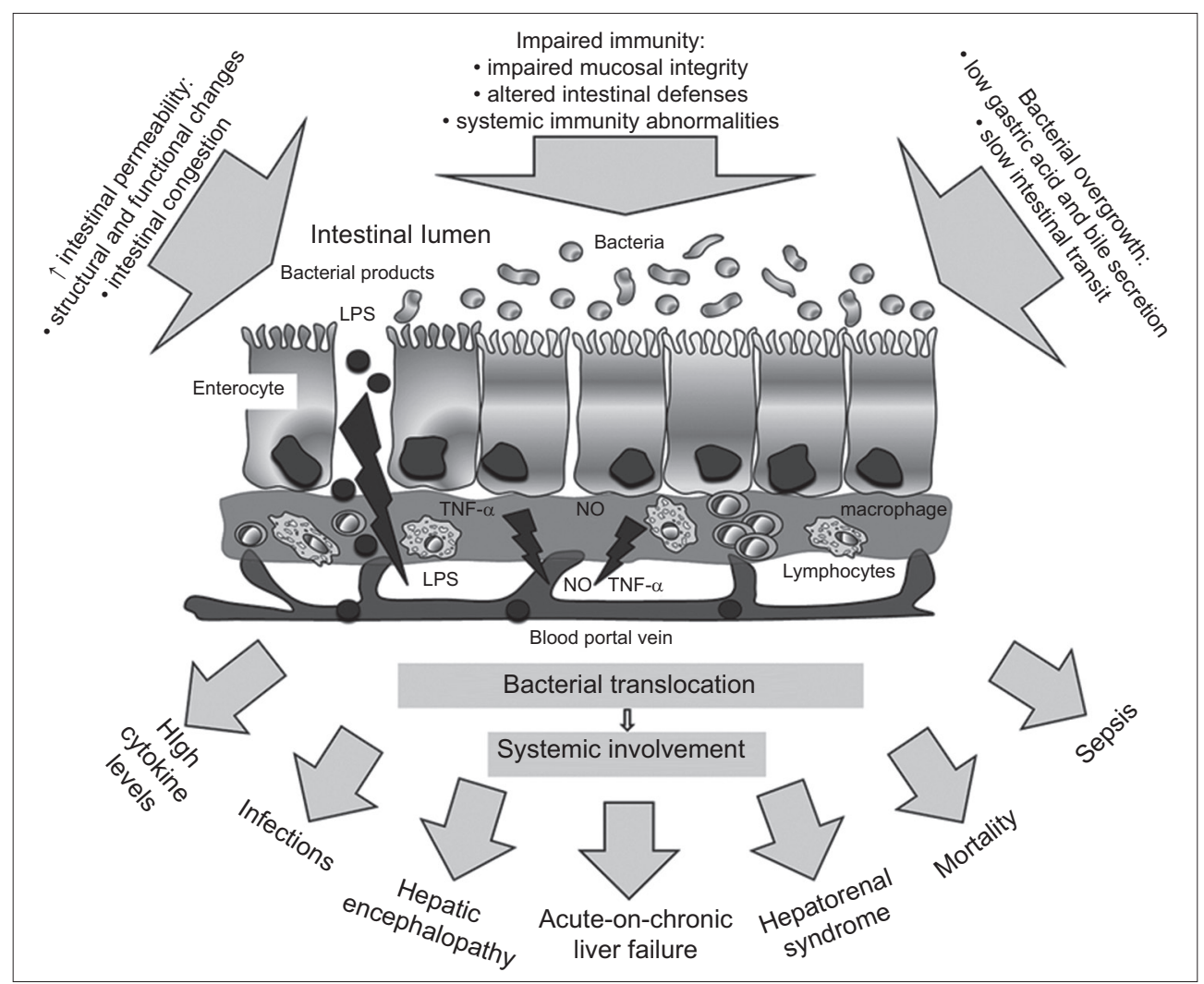

Figure 1 Mechanisms of bacterial translocation in liver cirrhosis.

Factors involved in the process of bacterial translocation include increased intestinal permeability, impaired immunity and bacterial overgrowth. These alterations may lead to migration of bacteria/bacterial products to either the systemic circulation or the mesenteric lymph nodes, causing a wide range of clinical manifestations, including hemodynamic instability, high proinflammatory cytokine levels, development of severe or recurrent infections, acute-on-chronic liver failure, hepatic encephalopathy, hepatorenal syndrome and poor prognosis

LPS, lipopolysaccharide; NO, nitric oxide; TNF- $\alpha$, tumor necrosis factor- $\alpha$ 
layer on the mucosa that prevents bacterial penetration. Mucous secretions are rich in immunoglobulin A, which neutralizes toxins and microorganisms and prevents their adhesion and colonization [13,25]. Bile acid secretion also plays a role in intestinal permeability by affecting intestinal mucosa and by neutralizing endotoxin [14]. In cirrhosis with portal hypertension, the microcirculation in the intestinal mucosa is disturbed, resulting in a reduction of mucosal blood flow that leads to congestion, edema, ischemia, and potentially to erosions and impaired mucosal integrity [23]. It has been shown that patients with advanced cirrhosis and previous episodes of SBP, hepatic encephalopathy or sepsis displayed high intestinal permeability $[26,27]$.

\section{Impaired immunity}

The intestine is an active organ of the immune system that contains every type of white blood cells involved in both innate and adaptive immune response. Bacteria that translocate to the mesenteric lymph nodes are usually neutralized before they cause infections in immunocompetent individuals [12]. In advanced cirrhosis, local immunity changes such as impaired mucosal integrity, altered intestinal defenses and systemic immunity abnormalities (Fig. 1) such as deficiency in bactericidal and opsonic function, low serum complement concentration, defective monocyte activity and chemotaxis may promote the development of BT [23]. Moreover, the phagocytic role of the reticuloendothelial system (which is represented in the liver by Kupffer cells) may be disordered, and the presence of portosystemic shunts explain the failure to eradicate bacteria and endotoxins [28].

Moreover, it is worth mentioning that bacteria and bacterial products are associated with a marked immune response, as shown by elevated levels of proinflammatory cytokines such as interleukin (IL)-6 and -12, tumor necrosis factor (TNF)- $\alpha$, interferon (IFN) $-\gamma$, and effector molecules such as NO $[29,30]$. Therefore, the high inflammatory response associated with BT acts on intestinal barrier function, inducing further derangement in both mucosal integrity and the intestinal immune system, favoring the translocation of bacteria and bacterial products and thus creating a positive feedback mechanism.

BT in cirrhosis has a significant clinical impact, as it leads to both increased susceptibility to bacterial infections [31] and a high systemic inflammatory response, resulting in an increase in portal pressure, disturbance of hemodynamic markers, deterioration of hepatic failure and worsening of hemostasis $[12,13]$. Considering the importance of BT in this setting, it would be of great interest to evaluate the surrogate markers of BT and their role in the severity and prognosis of liver disease.

\section{Materials and methods}

Relevant articles in English published between 1987 and 2016 were extensively searched from the databases of Medline
(PubMed), the Cochrane Library, Scopus and Google Scholar. The key words used for the search were "markers", "bacterial translocation", "cirrhosis", "c-reactive protein", "procalcitonin", "bacterial DNA", "lipopolysaccharide", "lipopolysaccharidebinding protein", "CD14", "calprotectin", and "bactericidal/ permeability increasing protein". These words were used individually or with the Boolean operator "AND". Initially, 63 articles were identified. Reviews and meta-analyses were excluded. Authors AA and DA were responsible for the literature search. We carefully checked the titles and abstracts of all returned articles. References listed in these articles were also reviewed. If several publications reported on a single study, the publication that provided the most data was selected. Monocyte or other activation biomarkers, such as mannose receptor, sCD163 and soluble urokinase plasminogen activator receptor (suPAR) were omitted, as they correlate more strongly with organ failure than with BT.

\section{BT markers}

\section{C-reactive protein (CRP) and procalcitonin (PCT)}

CRP and PCT have been widely used as acute-phase proteins and BT biomarkers (Tables 1,2). As the infections in cirrhosis are usually subclinical, it is difficult to differentiate whether these parameters are indicative of infection or whether they represent BT markers. There is controversy regarding the accuracy of BT diagnosis and the cutoff values of these markers in patients with liver cirrhosis. CRP is produced by hepatocytes [32,33] and its production may therefore be downregulated in advanced chronic liver failure. Silvestre et al [34], who studied patients with sepsis and fulminant hepatic failure, found that CRP was significantly decreased, suggesting that this marker should not be used in cases of severe liver dysfunction. On the other hand, CRP is promoted by IL-6, a proinflammatory IL upregulated in advanced liver disease $[32,33]$. Its value reflects the degree of systemic inflammation, regardless of the underlying cause. Cervoni et al [35] studied 148 consecutive patients with decompensated cirrhosis (including 37.2\% with infection at baseline) who were followed for 182 days. Investigators evaluated CRP as a surrogate marker of systemic inflammatory response and found that CRP levels were higher in patients who developed systemic inflammatory response syndrome, infection, and alcoholic hepatitis. Short-term mortality was associated with high baseline CRP levels. The CRP cutoff of $29 \mathrm{mg} / \mathrm{L}$ was the optimal value (receiver operating characteristic [ROC] analysis, area under the curve [AUC] 0.63). In multivariate analysis, CRP was one of the predictors of mortality [35]. Likewise, Cervoni et al [36] assessed the prognostic value of sustained high CRP levels (at least $29 \mathrm{mg} / \mathrm{L}$ both at baseline and at day $15 \pm 6$ ) in 583 patients with decompensated cirrhosis (Child-Pugh score $>$ B7) who were enrolled in the CANONIC cohort $(20 \%$ had bacterial infection at baseline). In multivariate analysis, predictors related to 3-month mortality were high model for end-stage liver disease (MELD) score, age, and persistently elevated CRP. 
Another large study by Papp et al [37], including 368 cirrhotic patients $(37.7 \%$ with infection), showed that CRP, PCT and lipopolysaccharide-binding protein (LBP) levels were significantly higher in patients with overt infections. More specifically, a CRP cutoff value of $10 \mathrm{mg} / \mathrm{L}$ proved to be the most accurate factor for identifying infection at baseline (AUC 0.93). On the other hand, in patients without overt infections, a CRP value of $>10 \mathrm{mg} / \mathrm{L}(\mathrm{P}=0.035)$ was demonstrated to be a good prognostic factor for the development of clinically significant bacterial infection during a 3-month follow-up period. The performance of PCT was rather inferior compared to CRP (cutoff value $0.15 \mu \mathrm{g} / \mathrm{L}$ for predicting infection with sensitivity of $72 \%$, specificity of $84 \%$ and AUC 0.84 ). However, the combination of CRP and PCT offered an increase in sensitivity and negative prognostic value by $10 \%$ and $5 \%$, respectively, compared to CRP alone [37]. Other studies illustrated that short-term mortality was related to high values of both CRP and PCT $[38,39]$. More specifically, CRP or PCT levels of $>29.5 \mathrm{mg} / \mathrm{L}$ or $>1.10 \mathrm{ng} / \mathrm{mL}$ showed a sensitivity of $82 \%$ or $67 \%$ and specificity of $81 \%$ or $90 \%$, respectively, in the diagnosis of infection. Significantly elevated CRP and PCT values were observed among patients who died within three months after admission, according to the study of Lazzarotto et al [38] (including 29.6\% admissions with infection).

A recent retrospective study by Ximenes et al [40], involving 149 patients with decompensated cirrhosis (including 48.3\% infections at baseline), reported that patients with infection showed CRP concentrations higher than $59.4 \mathrm{mg} / \mathrm{L}$ as well as lymphopenia $\left(\leq 900 / \mathrm{mm}^{3}\right)$. However, CRP was not a predictor of mortality in multivariate analysis. Measurement of high sensitivity CRP (hs-CRP) in ascitic fluid was performed by Kadam et al [41]. One hundred patients were studied (50 with SBP and 50 with sterile ascites). Patients with SBP were proved to have significantly higher hs-CRP ascitic fluid levels compared to those without SBP (77.50 vs. $42 \mathrm{mg} / \mathrm{dL})$, which declined after antibiotic treatment. According to a study by Tsiakalos et al [42], in which 88 consecutive cirrhotic patients were studied (21.6\% had documented infection at baseline), CRP offered the best diagnostic accuracy (AUC 0.91) compared to other acute phase proteins (fibrinogen, haptoglobin, ferritin, $\beta 2$-microglobulin, and complement levels) in discriminating infection. More specifically, a cutoff value of $>55.8 \mathrm{mg} / \mathrm{L}$ offered a sensitivity of $79 \%$ and specificity of $96 \%$ [42]. Connert et al [43] showed that serum PCT levels were higher in patients with documented infection compared to those without and were associated with $50 \%$ mortality in the first two months. In this study, 127 cirrhotic patients were followed and divided into three groups: decompensated cirrhosis with infection (28.3\%), decompensated cirrhosis without infection and compensated cirrhosis without infection. PCT levels varied significantly among the groups and a concentration of $0.58 \mathrm{ng} / \mathrm{mL}$ was the best cutoff value for discriminating infection (sensitivity $92 \%$ and specificity 78\%). PCT in ascitic fluid appeared to be a less accurate marker in identifying underlying infection [43]. Ascitic fluid PCT has been studied in patients with decompensated cirrhosis and SBP (SBP in 31.2\%) and has been found not to correlate with other laboratory parameters, according to the results of Lesinska et al [44]. Viallon et al [45] demonstrated that PCT in serum and IL- 6 in ascitic fluid were the best surrogate markers for the diagnosis of SBP in 21 cirrhotic patients with SBP (34.4\% of the total) and 40 patients with sterile ascites. The serum PCT cutoff of $0.75 \mathrm{ng} / \mathrm{mL}$ was the optimal value, offering a sensitivity of $95 \%$ and a specificity of $98 \%$ in differentiating between patients with and without SBP.

\section{LPS, LBP and sCD14}

The LPS or endotoxin is the main component of Gramnegative bacteria (section of the outer membrane) and is a BT marker when detected in the systemic circulation [46,47]. It consists of a lipid and a polysaccharide molecule. LPS has a short half-life (2-3 h) and is influenced by many factors, including the concentration of LPS transporters, antibodies, high-density lipoproteins, and other immunogenic and microbiological parameters $[48,49]$. The transient character and the parameters mentioned above prevent LPS from being considered as a reliable surrogate marker of BT. Old studies demonstrated that plasma LPS values in alcoholic cirrhosis were significantly higher than in non-alcoholic and appeared to be correlated with proinflammatory cytokine values (TNF- $\alpha$ levels) and the stage of liver disease (Child-Pugh) (Table 1) [50,51].

LBP is an acute-phase protein (molecular weight $60 \mathrm{KDa}$ ) produced by hepatocytes in response to bacteremia and endotoxemia [52]. It binds specifically to the lipid A of bacterial LPS to facilitate its transfer to cell receptors such as CD14 [52]. Thus, the LPS-LBP complex binds to CD14 in myeloid cells and promotes an inflammatory response cascade [53-56]. Kupffer cells, which are specialized macrophages of the liver, are activated when exposed to LPS and produce cytokines such as TNF- $\alpha$, IL-1, IL-6, and IL-12, a mechanism implicated in the pathogenesis of liver injury [57]. Due to its long halflife (2-3 days) [58], LBP levels are displayed for a prolonged time in serum after an episode of bacteremia and it is a relatively reliable marker for the diagnosis of BT (Tables 1,2 ). Increased LBP levels have been found to be associated with hemodynamic instability in cirrhotic patients and predict the development of bacterial infection [59,60]. More specifically, in the study of Albillos et al [59] (no infected patients were included as infection was in the exclusion criteria), 102 cirrhotic patients and 30 controls were followed and LBP and soluble CD14 (sCD14) were detected before and four weeks after norfloxacin or placebo treatment. LBP values were significantly more elevated in patients with ascites compared to those without $(\mathrm{P}<0.01)$. It was also observed that increased levels of serum LBP in cirrhotic patients correlated with high sCD14, TNF- $\alpha$, and IL-6 values. In patients with high LBP, norfloxacin treatment normalized both LBP levels and sCD14. Moreover, Albillos et al [60] (infection on admission was an exclusion criterion) demonstrated that serum LBP levels in 84 cirrhotic patients with ascites was the only factor in the multivariate analysis associated with severe bacterial infection (relative risk 4.49, 95\% confidence interval 1.42-14.1) during a 46-week follow-up period. LBP values were found to be elevated in patients with severe portal hypertension compared to those with low portal pressure and decreased 
Bacterial translocation markers in liver cirrhosis $\mathbf{5}$

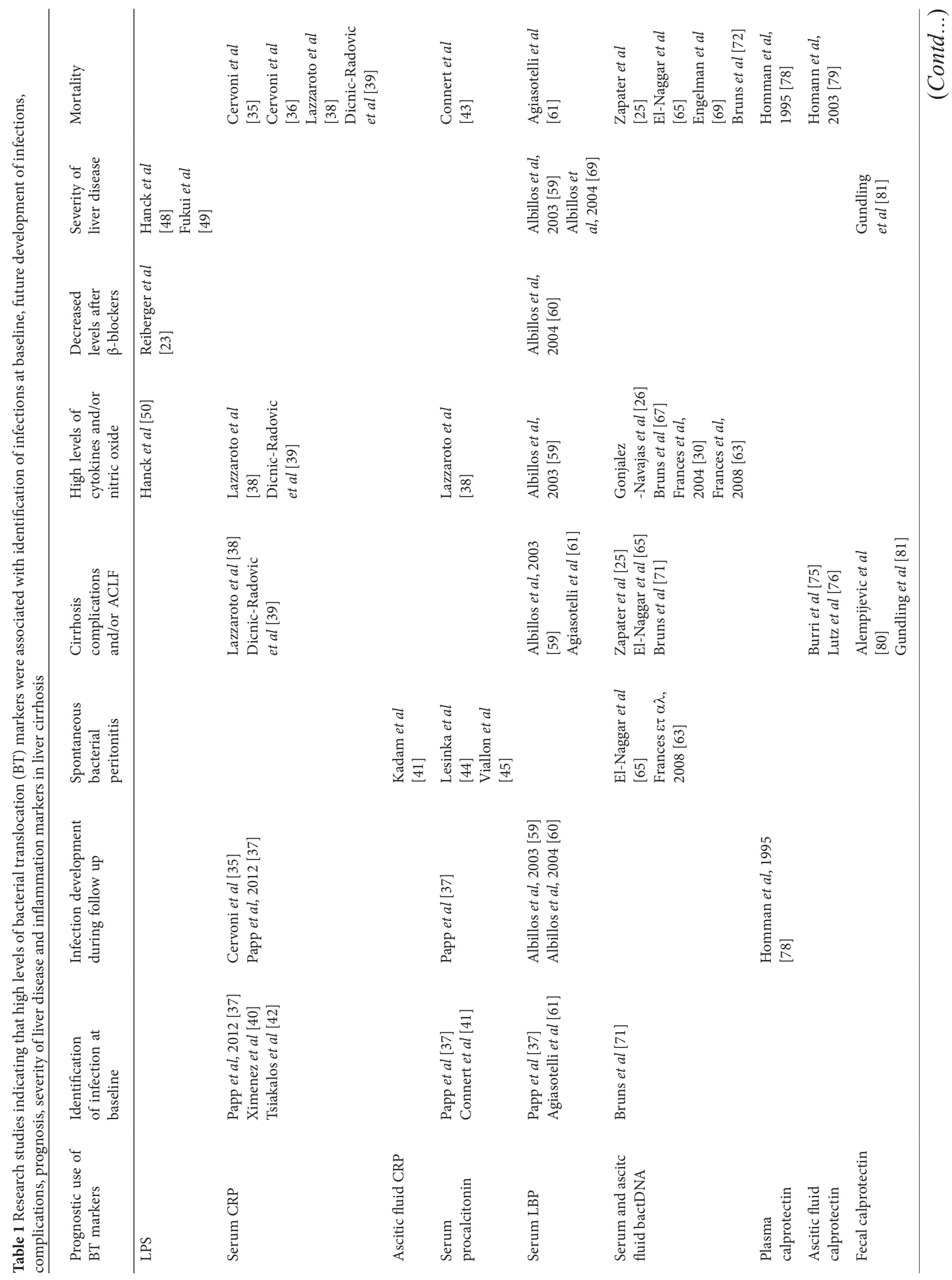




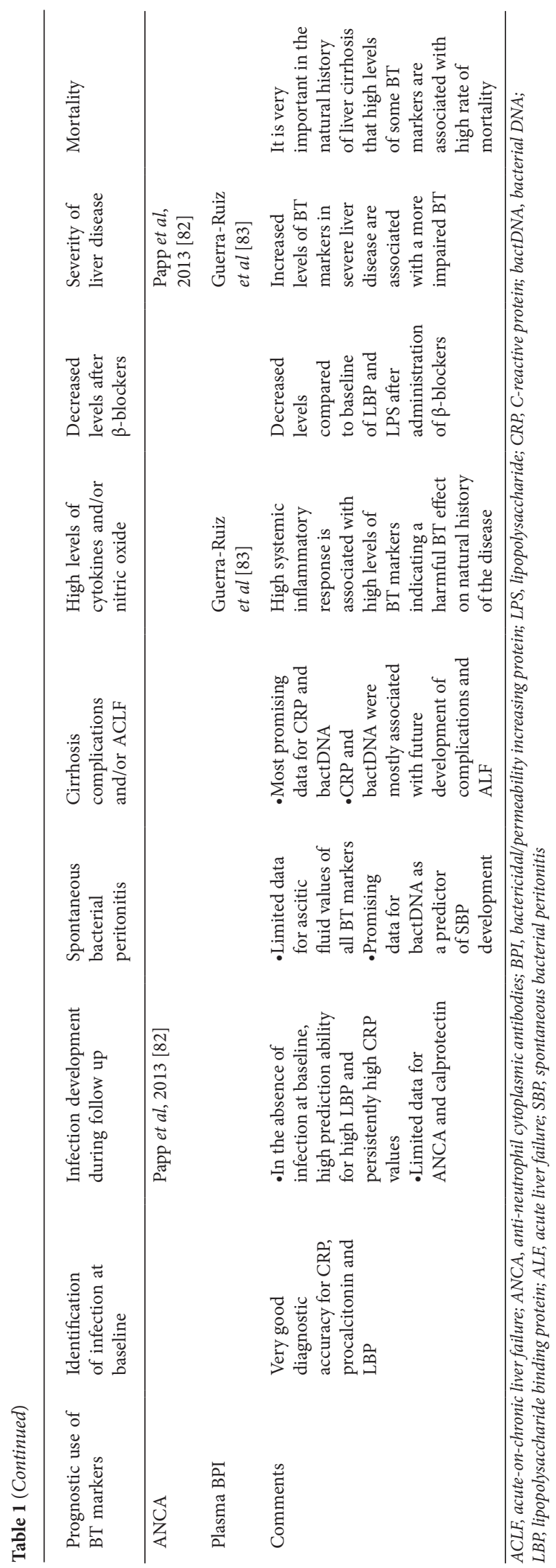

after non-selective $\beta$-blocker treatment (mean decrease $16 \%)[60]$, a finding that may be associated with a beneficial effect of $\beta$-blockers on intestinal permeability and BT [23]. It has also been shown that serum LBP values are associated with Gram-negative, but not Gram-positive bacteria, since they are elevated only in patients with bacterial DNA (bactDNA) from Gram-negative microorganisms [26]. Furthermore, it is noteworthy to mention the study by Agiasotelli et al [61], who assessed serum and ascitic fluid LBP and examined their association with mortality in patients with decompensated cirrhosis. More specifically, 88 consecutive patients $(20.4 \%$ with infection) were included and underwent investigation for infection. Serum LBP was higher in 18 patients with infection compared to those without $(\mathrm{P}<0.001)$. Serum and ascitic fluid LBP showed a positive correlation with surrogate markers of inflammation and displayed a very good negative predictive value for ruling out infection and SBP. In ROC curve analyses, serum natural logarithm LBP showed good diagnostic accuracy in discriminating patients with from those without infection (c-statistic 0.773). The optimal cutoff of 13.49 offered a sensitivity of $72.2 \%$, a specificity of $64.3 \%$, a negative predictive value of $90.0 \%$, and a positive predictive value of $34.2 \%$ in discriminating infection. CRP showed a lower diagnostic accuracy (c-statistic 0.708). The optimal cutoff of $23.65 \mathrm{mg} / \mathrm{L}$ offered a sensitivity of $61.1 \%$, a specificity of $60.0 \%$, a negative predictive value of $85.71 \%$, and a positive predictive value of $28.20 \%$. In univariate Cox regression analysis, neutrophils, LBP, MELD score, and CRP were predictive of mortality. However, only high LBP and MELD score were predictive of mortality in multivariate analysis.

\section{BactDNA}

Circulating and peritoneal fluid fragments of bactDNA is a modern BT parameter. Its detection by the polymerase chain reaction (PCR) is associated with a systemic inflammatory response and poor prognosis of liver disease (Tables 1,2) [14]. Such et al [62] (no infection included) showed that bactDNA was detected in both serum and ascitic fluid in one third of cirrhotic patients with non-neutrocytic ascites and negative ascitic fluid culture indicating bactDNA presence. E. coli was the most frequently and Staphylococcus aureus the less frequently detected nucleotide sequence. In other research [29], BactDNA was detected in 7 of 17 patients with non-neutrocytic ascites, in both serum and peritoneal fluid (no infection included). Therapeutic paracentesis was performed at the time of admission and serum samples were obtained at baseline and every 8 h over a 3 -day period. The nucleotide sequencing method illustrated that bacteria detected in the first were identical to those identified in subsequent samples. BactDNA fragments persisted in blood for a period of 24-72 $\mathrm{h}$ in some patients, a phenomenon that was related to the presence of recurrent BT episodes [29]. Furthermore, Frances et al [30] evaluated 10 patients with cirrhosis and non-neutrocytic ascitic fluid (no infection included). Peritoneal macrophages were collected and characterized by flow cytometry. The authors concluded 
Table 2 The pros and cons of bacterial translocation (BT) biomarkers

\begin{tabular}{|c|c|c|}
\hline BT markers & Pros & Cons \\
\hline Lipopolysaccharide & - The first BT marker & -Short half-life \\
\hline Serum C-reactive protein & $\begin{array}{l}\text { - Persistent high values in the absence of infection at } \\
\text { baseline are predictive of high 3-month mortality } \\
\text { rate } \\
\text {-High values at baseline without overt infection are } \\
\text { predictor of infection development } \\
\text {-Cheap method }\end{array}$ & $\begin{array}{l}\text {-It is mainly used as an acute phase protein } \\
\text { indicative of infection } \\
\text {-It lacks specificity as BT marker } \\
\text {-It is downregulated in advanced liver disease }\end{array}$ \\
\hline Serum procalcitonin & Cheap method & $\begin{array}{l}\text {-It lacks specificity as BT marker } \\
\text {-It was mainly used to differentiate infection } \\
\text { from non infection }\end{array}$ \\
\hline Soluble CD14 & $\begin{array}{l}\text {-It is correlated with markers of inflammation and } \\
\text { liver disease activity }\end{array}$ & -A less well-studied marker \\
\hline $\begin{array}{l}\text { Serum lipopolysaccharide-binding } \\
\text { protein }\end{array}$ & $\begin{array}{l}\text {-It has a prolonged half life } \\
\text { - High values at baseline without overt infection are } \\
\text { predictor of infection development } \\
\text {-It is correlated with severity of liver disease and } \\
\text { portal hypertension }\end{array}$ & $\begin{array}{l}\text {-It is an acute phase protein and it is } \\
\text { increased in infection episodes } \\
\text {-Expensive method }\end{array}$ \\
\hline $\begin{array}{l}\text { Serum and ascitic fluid bacterial } \\
\text { DNA }\end{array}$ & $\begin{array}{l}\text {-Positively correlated with proinflammatory } \\
\text { cytokines } \\
\text {-Persistence for long time in serum } \\
\text {-Its presence is correlated with complications of } \\
\text { cirrhosis }\end{array}$ & $\begin{array}{l}\text {-Non-standardized method } \\
\text { •Its clinical relevance in BT is not well } \\
\text { validated }\end{array}$ \\
\hline $\begin{array}{l}\text { Plasma, ascitic fluid and fecal } \\
\text { calprotectin }\end{array}$ & $\begin{array}{l}\text {-Its presence is correlated with complications of } \\
\text { cirrhosis and poor survival }\end{array}$ & $\begin{array}{l}\text {-Its role is mainly validated in inflammatory } \\
\text { bowel disease } \\
\text {-Its clinical relevance in BT of cirrhosis is not } \\
\text { well investigated }\end{array}$ \\
\hline $\begin{array}{l}\text { Anti-neutrophil cytoplasmic } \\
\text { antibodies }\end{array}$ & $\begin{array}{l}\text {-It is correlated with severity of liver disease } \\
\text {-It is associated with future infection episodes }\end{array}$ & $\begin{array}{l}\text { Its role in BT of cirrhosis is not well } \\
\text { investigated }\end{array}$ \\
\hline $\begin{array}{l}\text { Plasma bactericidal/permeability } \\
\text { increasing protein }\end{array}$ & $\begin{array}{l}\text {-It is correlated with severity of liver disease and high } \\
\text { inflammatory response }\end{array}$ & $\begin{array}{l}\text {-Its role in BT of cirrhosis is not well } \\
\text { investigated }\end{array}$ \\
\hline
\end{tabular}

that peritoneal macrophage activation was associated with the production of NO and cytokines (IFN- $\gamma$, TNF- $\alpha$, IL-2, IL-12), indicating that bactDNA is a factor in BT and is involved in the activation of liver macrophages, inducing cell mediated immune response and NO production [30]. Subsequently, the same group [63] investigated 226 patients with cirrhosis and non-infected ascites, 22 patients with SBP and 10 patients with ascites receiving continuous norfloxacin. They showed that bactDNA was present in $34 \%$ of non-infected patients and in all patients with SBP, even in those with culture-negative ascitic fluid, but was absent in those receiving norfloxacin. Levels of all cytokines in serum and ascitic fluid were higher in patients with positive bactDNA compared to those without.

Likewise, Gonzales-Navajas et al reported that cirrhotic patients with positive bactDNA (infection was excluded) displayed increased proinflammatory cytokine concentrations (TNF- $\alpha$ and IL-6) [26]. In addition, bactDNA levels were higher in patients with Gram-negative than in those with Grampositive bacteria $[26,64]$. A relevant report (positive culture of blood and ascites and SBP were excluded) demonstrated that serum and ascitic fluid bactDNA was positively correlated with TNF- $\alpha$ and NO levels [64].
BactDNA was also used as a marker of prognosis and survival in liver disease. Zapater et al [25] demonstrated that the presence of bactDNA in serum and ascites of cirrhotic patients without overt infection is a marker of poor prognosis and is probably related to the development of acute-on-chronic liver failure, but did not predict SBP development. Another investigation by El-Naggar et al [65] illustrated that serum and ascitic fluid TNF- $\alpha$ was significantly higher in patients with evidence of bactDNA compared to those without (no infection included), while most importantly, patients with bactDNA had a higher relative risk for death, hepatorenal syndrome and SBP.

In contrast, an investigation by Sersté et al [66], which included 31 cirrhotic outpatients with non-neutrocytic ascites (no infection included), 18 of whom had several consecutive paracenteses over a 13-week period, reported that bactDNA was rarely detected in serum or ascites. Mortensen et al [67] evaluated bactDNA in blood obtained by the portal and hepatic veins in cirrhotic patients undergoing transjugular intrahepatic portosystemic shunt insertion (no infection included). The investigators showed that no transhepatic gradient of bactDNA was evident, suggesting that no major hepatic elimination of bactDNA occurs in advanced liver disease. They also 
observed that bactDNA levels were not related to markers of inflammation and portal pressure [67].

Similar results were reported by Krohn et al [68] in 356 ascites samples from cirrhotic patients with end-stage liver disease. BactDNA was detected in 35\% of ascitic fluid samples and only a small proportion of bactDNA-positive samples showed positive culture results (3\%). Mean bactDNA quantities were higher in culture-positive than in culturenegative samples. Most bactDNA-positive samples (79\%) showed a total leukocyte count in ascites below or equal to 500 cells $/ \mathrm{mm}^{3}$. Polymicrobial DNA contents were identified in $67 \%$ of bactDNA-positive ascites samples.

Engelmann et al [69] suggested the new term "molecular bacterascites" and quantified bactDNA in ascitic fluid samples using a culture-independent $16 \mathrm{~S}$ rRNA gene-based method. They demonstrated that patients' survival was positively associated with bactDNA levels.

All the five aforementioned studies [66-69] demonstrated that the clinical and diagnostic relevance of bactDNA in patients with liver cirrhosis has not been well documented [70]. In all the above studies, bactDNA was determined by PCR for the universal amplification of a region of the $16 \mathrm{~S}$ ribosomal RNA (16SrRNA) gene followed by nucleotide sequencing. In a number of studies, a qualitative PCR was used to detect the presence or absence of bactDNA $[25,26,30,62,64,66]$, while in others a quantification of bactDNA was performed [29,63,67,69]. Recently, more standardized methods, such as multiplex PCR, and different patient cohorts have been used. For instance, in a recent research work by Bruns et al [71] bactDNA was detected by multiplex polymerase chain reaction in serum and/ or ascitic fluid in $61 \%$ of patients with suspected infection at baseline. BactDNA was associated with SBP and bacteremia, acute-on-chronic liver failure, encephalopathy and markers of inflammation, but was not a predictor of survival. However, the detection of resistance genes in blood or ascitic fluid in the absence of overt infection was associated with poor 1-year survival. In another study by Bruns et al [72], 68 consecutive patients were evaluated and underwent diagnostic paracentesis of ascitic fluid, which was further analyzed for neutrophils, bacterial culture and bactDNA by multiplex PCR. BactDNA was detected in 5/5 culture-positive neutrocytic ascitic samples, in 1/6 culture-negative neutrocytic ascites samples and in 8/56 culture-negative non-neutrocytic samples. Threemonth mortality did not differ according to the bactDNA status. However, patients older than 65 years, with severe liver disease and positive bactDNA had shorter survival.

\section{Calprotectin}

Calprotectin is a calcium- and zinc-binding protein of granulocytes and an established marker for the assessment of localized intestinal inflammation [73]. The presence of fecal calprotectin is related to intestinal neutrophil migration [74]. Fecal calprotectin has been studied mostly in gastrointestinal (GI) disorders as a diagnostic and prognostic marker, especially in inflammatory bowel disease [75]. As the GI tract of cirrhotic patients has evidence of various alterations of its mucosal barrier, calprotectin might be a promising diagnostic parameter for BT (Table 1). Ascitic fluid calprotectin is a surrogate marker for the presence and prognosis of SBP, according to studies by Burri et al and Lutz et al [76,77]. More specifically, Burri et al [76] prospectively studied 130 ascitic samples from 71 cirrhotic patients and reported that ascitic fluid calprotectin levels were higher in samples with polymorphonuclear cell count $>250 / \mu \mathrm{L}$, The cutoff of $0.63 \mu \mathrm{g} / \mathrm{mL}$ was the optimal value, with a sensitivity of $94.8 \%$ and a specificity of $89.2 \%$. Likewise, Lutz et al [77] (patients with and without infection were included) studied 120 ascitic fluid samples from 100 cirrhotic patients and showed that samples without infection had significantly lower calprotectin levels (median $34 \mathrm{ng} / \mathrm{mL}$ ) than SBP samples (median $928 \mathrm{ng} / \mathrm{mL}$ ). Furthermore, the ratio of calprotectin to total protein in ascitic fluid was a better surrogate marker for SBP diagnosis than calprotectin alone (AUROC 0.93, $\mathrm{P}<0.001$, sensitivity $93 \%$, specificity $79 \%$ ) and high levels of the ratio were associated with poor 30-day survival [77]. Homann et al in 1995 [78] showed that plasma calprotectin seemed to be a predictor of recurrent infection and poor prognosis in alcoholic cirrhosis. Similar results were demonstrated for ascitic fluid, showing that calprotectin was a predictor of survival in alcoholinduced liver disease [79]. The research work by Alempijević et al [80] highlighted the role of fecal calprotectin in patients with hepatic encephalopathy. Higher values of this protein were found in patients with hepatic encephalopathy comparing to healthy controls. Another study by Gundling et al [81] focused on the role of fecal calprotectin concentrations in evaluating the onset and severity of SBP and hepatic encephalopathy. More specifically, 61 cirrhotic patients and 42 healthy controls were studied and stool samples were collected. Median fecal calprotectin values were higher in cirrhotic patients compared with controls ( 65.8 vs. $17.5 \mathrm{mg} / \mathrm{kg}, \mathrm{P}<0.001)$. Fecal calprotectin concentrations were dependent on the severity of liver disease expressed by Child-Pugh and MELD scores, as well as on SBP and grade of hepatic encephalopathy.

\section{Other BT markers}

Anti-neutrophil cytoplasmic antibodies (ANCA) comprise a family of antibodies that recognize diverse components of neutrophil granulocytes [82]. ANCA formation may be induced by underlying bacterial infections, probably reflecting an abnormal immune response to bacteria. A study by Papp et al [82] stressed the clinical importance of the IgA class ANCA in cirrhosis and showed that its prevalence was higher in 385 cirrhotic patients compared to 202 patients with chronic liver disease without cirrhosis or to 100 healthy controls. IgA class ANCA presence was significantly associated with severity of liver disease, as indicated by the Child-Pugh score and the presence of ascites. In addition, the risk of infection was higher among patients with class IgA ANCA compared to those without $(41.8 \%$ vs. $23.4 \%, \mathrm{P}<0.001)$ during a 2 -year follow-up period. ANCA IgA presence was associated with a shorter time to the development of the first infection and was identified 
as an independent predictor of future infection episodes in multivariate Cox-regression analysis (Table 1).

Bactericidal/permeability increasing protein (BPI) [83] is a protein found in neutrophils that has endotoxin-binding and neutralization capacity. It has been assessed to be high (BPI mRNA and plasma BPI) in patients with advanced liver disease and plasma BPI levels correlated with TNF- $\alpha$. High levels of BPI in plasma were able to significantly reduce in vitro TNF- $\alpha$ release by monocytes after a challenge with LPS. The authors suggested that BPI possibly had a regulatory role by antagonizing the proinflammatory response mediated by TNF- $\alpha$ (Table 1) [83]. A promising tool that has recently been mentioned in studies is human $\beta$ defensin-1 (hBD-1) [15]. Defensins are natural antimicrobial peptides derived from Paneth cells and epithelial cells, T cells and neutrophils. They have broad antimicrobial activity that includes Gram-negative and Gram-positive bacteria, viruses and fungi [15]. Kaltsa et al [84] investigated the role of hBD-1 as a surrogate marker of pathological BT. Three groups of patients were compared: cirrhotic patients, patients with chronic viral hepatitis but no cirrhosis, and healthy controls. This study found higher plasma concentrations of hBD-1 in cirrhotic patients compared to both the other groups, a difference that was sustained when cirrhotic viral hepatitis patients were compared to noncirrhotic ones. Levels of sCD14 correlated significantly with hBD-1 in the hepatic venous blood of cirrhotic patients but not in the peripheral blood [84].

\section{Concluding remarks}

Infections are associated with increased mortality in patients with decompensated cirrhosis and are a precipitating event in acute-on-chronic liver failure. The most common underlying mechanism of bacterial infections in patients with cirrhosis is abnormal BT. BT disorder is also associated with an advanced stage of liver disease, a high inflammatory response, development of other complications of cirrhosis such as hepatic encephalopathy, hepatorenal syndrome, variceal bleeding, and poor survival.

CRP and PCT are inexpensive surrogate markers and have been widely used for the diagnosis of infection and BT. However they are produced by the liver and their synthesis may be impaired in advanced liver failure. In addition, they lack specificity, as increased levels of these markers may not be indicative of BT disorder but of a latent bacterial infection. Infection is often difficult to diagnose and empiric antibiotic treatment is frequently prescribed. This carries the longterm risk of potentially increasing rates of antimicrobial resistance. Investigators showed that serum CRP and PCT have good diagnostic accuracy in discriminating patients with or without infection. However, there is controversy among studies regarding the clinically significant cutoff levels that may differentiate infected from non-infected cirrhotic patients, ranging from 29 to $59.4 \mathrm{mg} / \mathrm{L}$ and from 0.58 to $1.10 \mathrm{ng} / \mathrm{mL}$ for CRP and PCT, respectively. Hence, if these findings could be incorporated into clinical practice, empiric antibiotics should be administered in patients with high values but borderline documentation of infection and stopped in those with low values and no definitive evidence of infection.

As CRP and PCT are acute phase proteins and are elevated in the case of infection, investigators excluded cases with infection at baseline and considered that patients with persistently high CRP levels in the absence of infection have impaired BT. They also demonstrated that persistently high CRP or PCT levels without documented infection at baseline may predict the development of infection during follow up.

LPS is not used any more because of its short half life and consequent low sensitivity. LBP has a prolonged half life and is still a promising surrogate marker of BT in liver cirrhosis. High LBP levels are associated with hemodynamic instability and susceptibility to developing infections. Similar to CRP and PCT, LBP levels could be used as a surrogate marker to discriminate infection and find patients who have no infection at baseline but are at high risk of developing infection during follow up. First, it was shown that LBP displayed a better negative predictive value to rule out infection. Second, high LBP levels were identified in patients with decompensated cirrhosis, but no evidence of infection, who died during the following 90 -day period, a finding probably related to mechanisms of abnormal intestinal permeability and BT. In addition, antibiotics and treatment with $\beta$-blocker decrease LBP levels, denoting a decline in BT disorder. A limitation of LBP assessment in clinical practice is the high cost of the test. Hence, the routine use of this tool in everyday clinical practice is questionable because of the complexity of the assay and its high cost.

BactDNA is a new investigative marker of BT. Its persistence for a long time in serum is well documented. It is present in about one third of patients with cirrhosis without infection and two thirds of patients with suspected infection. Its presence is associated with elevated inflammatory indexes, complications of cirrhosis, acute-on-chronic liver failure, and poor prognosis. BactDNA is a better marker than endotoxin (LPS), as it persists in blood for a long period of 1-3 days and is associated with an immune activation mechanism, suggesting that the impaired process of translocation may be due to bacterial products as opposed to viable microorganisms. Recently, bactDNA quantification in ascitic fluid samples using cultureindependent methods seems to be an interesting approach for identifying patients at risk of cirrhosis complications, acute-on-chronic liver failure, and/or low survival. The new term "molecular bacterascites" means a culture-negative, non-neutrocytic ascites, rich in bactDNA, which seems to be associated with high mortality rates.

Plasma, peritoneal fluid and fecal calprotectin have been used as BT surrogate markers in cirrhosis and have been associated with the development of complications such as SBP and hepatic encephalopathy, severity of chronic hepatic failure and poor survival. More studies are needed for further evaluation of this marker.

IgA class ANCA presence has been significantly associated with the severity of liver disease and with the future development of infection episodes. A new promising marker, 
the bactericidal/permeability increasing protein, is associated with severity of liver disease/portal hypertension and high inflammatory response, respectively.

To date, all the aforementioned BT biomarkers have been used, but no single marker has been proved reliable for the prediction of infection and mortality. It is believed that bacterial infections in cirrhosis are often subclinical. However, the majority of the current surrogate markers do not allow the discrimination of sterile inflammation due to non-viable BT from infections by viable BT. The above markers have been detected in plasma, serum, peritoneal fluid, and/or stools. However, the optimal detection site has not been determined and the threshold levels where BT becomes pathologic have not been defined for each of the parameters. Even though their number is expanding and their role is increasingly studied in the literature, a valid and specific biomarker that could reliably evaluate the impact of BT in advanced liver disease is still needed.

Studies of acute kidney injury found that the removal of LBP from plasma was crucial for eliminating the effects of LPS on endothelial cell dysfunction and endotoxemia-related renal tissue fibrosis [85]. Removal of BT factors like bactDNA or LBP might represent a future therapeutic option to prevent the BT process and complications of cirrhosis.

\section{References}

1. Bunchorntavakul C, Chamroonkul N, Chavalitdhamrong D. Bacterial infections in cirrhosis: A critical review and practical guidance. World J Hepatol 2016;8:307-321.

2. Bartoletti M, Giannella M, Lewis RE, Viale P. Bloodstream infections in patients with liver cirrhosis. Virulence 2016;7:309-319.

3. Jalan R, Fernandez J, Wiest R, et al. Bacterial infections in cirrhosis: a position statement based on the EASL Special Conference 2013. J Hepatol 2014;60:1310-1324.

4. Fernández J, Navasa M, Gómez J, et al. Bacterial infections in cirrhosis: epidemiological changes with invasive procedures and norfloxacin prophylaxis. Hepatology 2002;35:140-148.

5. Fernández J, Gustot T. Management of bacterial infections in cirrhosis. J Hepatol 2012;56 Suppl 1:S1-S12.

6. Gustot T, Durand F, Lebrec D, Vincent JL, Moreau R. Severe sepsis in cirrhosis. Hepatology 2009;50:2022-2033.

7. Berg RD, Garlington AW. Translocation of certain indigenous bacteria from the gastrointestinal tract to the mesenteric lymph nodes and other organs in a gnotobiotic mouse model. Infect Immun 1979;23:403-411.

8. Wiest R, Rath HC. Gastrointestinal disorders of the critically ill. Bacterial translocation in the gut. Best Pract Res Clin Gastroenterol 2003; 17:397-425.

9. Steffen EK, Berg RD, Deitch EA. Comparison of translocation rates of various indigenous bacteria from the gastrointestinal tract to the mesenteric lymph node. J Infect Dis 1988;157:1032-1038.

10. Wells CL. Colonization and translocation of intestinal bacterial flora. Transplant Proc 1996;28:2653-2656.

11. Cirera I, Bauer TM, Navasa M, et al. Bacterial translocation of enteric organisms in patients with cirrhosis. J Hepatol 2001;34:32-37.

12. Wiest R, Garcia-Tsao G. Bacterial translocation (BT) in cirrhosis. Hepatology 2005;41:422-433.
13. Garcia-Tsao G, Lee FY, Barden GE, Cartun R, West AB. Bacterial translocation to mesenteric lymph nodes is increased in cirrhotic rats with ascites. Gastroenterology 1995;108:1835-1841.

14. Bellot P, García-Pagán JC, Francés R, et al. Bacterial DNA translocation is associated with systemic circulatory abnormalities and intrahepatic endothelial dysfunction in patients with cirrhosis. Hepatology 2010;52:2044-2052.

15. Cunliffe RN, Mahida YR. Antimicrobial peptides in innate intestinal host defence. Gut 2000;47:16-17.

16. Pinzone MR, Celesia BM, Di Rosa M, Cacopardo B, Nunnari G. Microbial translocation in chronic liver diseases. Int J Microbiol 2012;2012:694629.

17. Barbara G, Stanghellini V, Brandi G, et al. Interactions between commensal bacteria and gut sensorimotor function in health and disease. Am J Gastroenterol 2005;100:2560-2568.

18. Bauer TM, Schwacha H, Steinbrückner B, et al. Small intestinal bacterial overgrowth in human cirrhosis is associated with systemic endotoxemia. Am J Gastroenterol 2002;97:2364-2370.

19. Pardo A, Bartolí R, Lorenzo-Zúñiga V, et al. Effect of cisapride on intestinal bacterial overgrowth and bacterial translocation in cirrhosis. Hepatology 2000;31:858-863.

20. Bode C, Kolepke R, Schäfer K, Bode JC. Breath hydrogen excretion in patients with alcoholic liver disease--evidence of small intestinal bacterial overgrowth. Z Gastroenterol 1993;31:3-7.

21. Yang CY, Chang CS, Chen GH. Small-intestinal bacterial overgrowth in patients with liver cirrhosis, diagnosed with glucose H2 or CH4 breath tests. Scand J Gastroenterol 1998;33:867-871.

22. Sadik R, Abrahamsson H, Björnsson E, Gunnarsdottir A, Stotzer PO. Etiology of portal hypertension may influence gastrointestinal transit. Scand J Gastroenterol 2003;38:1039-1044.

23. Reiberger T, Ferlitsch A, Payer BA, et al; Vienna Hepatic Hemodynamic Lab. Non-selective betablocker therapy decreases intestinal permeability and serum levels of LBP and IL-6 in patients with cirrhosis. J Hepatol 2013;58:911-921.

24. Guarner C, Soriano G, Tomas A, et al. Increased serum nitrite and nitrate levels in patients with cirrhosis: relationship to endotoxemia. Hepatology 1993;18:1139-1143.

25. Zapater P, Francés R, González-Navajas JM, et al. Serum and ascitic fluid bacterial DNA: a new independent prognostic factor in noninfected patients with cirrhosis. Hepatology 2008;48:1924-1931.

26. González-Navajas JM, Bellot P, Francés R, et al. Presence of bacterial-DNA in cirrhosis identifies a subgroup of patients with marked inflammatory response not related to endotoxin. J Hepatol 2008;48:61-67.

27. Ruiz-del-Arbol L, Urman J, Fernández J, et al. Systemic, renal, and hepatic hemodynamic derangement in cirrhotic patients with spontaneous bacterial peritonitis. Hepatology 2003;38:1210-1218.

28. Rimola A, Soto R, Bory F, Arroyo V, Piera C, Rodes J. Reticuloendothelial system phagocytic activity in cirrhosis and its relation to bacterial infections and prognosis. Hepatology 1984;4:53-58.

29. Francés R, Benlloch S, Zapater P, et al. A sequential study of serum bacterial DNA in patients with advanced cirrhosis and ascites. Hepatology 2004;39:484-491.

30. Francés R, Muñoz C, Zapater P, et al. Bacterial DNA activates cell mediated immune response and nitric oxide overproduction in peritoneal macrophages from patients with cirrhosis and ascites. Gut 2004;53:860-864.

31. Arvaniti V, D'Amico G, Fede G, et al. Infections in patients with cirrhosis increase mortality four-fold and should be used in determining prognosis. Gastroenterology 2010;139:1246-1256, 1256.e1-5.

32. Bota DP, Van Nuffelen M, Zakariah AN, Vincent JL. Serum levels of C-reactive protein and procalcitonin in critically ill patients with cirrhosis of the liver. J Lab Clin Med 2005;146:347-351. 
33. Park WB, Lee KD, Lee CS, et al. Production of C-reactive protein in Escherichia coli-infected patients with liver dysfunction due to liver cirrhosis. Diagn Microbiol Infect Dis 2005;51:227-230.

34. Silvestre JP, Coelho LM, Póvoa PM. Impact of fulminant hepatic failure in C-reactive protein? J Crit Care 2010;25:657.e7-e12.

35. Cervoni JP, Thévenot T, Weil D, et al. C-reactive protein predicts short-term mortality in patients with cirrhosis. J Hepatol 2012;56:1299-1304.

36. Cervoni JP, Amorós, Bañares R, et al; EASL-CLIF Consortium. Prognostic value of C-reactive protein in cirrhosis: external validation from the CANONIC cohort. Eur J Gastroenterol Hepatol 2016;28:1028-1034.

37. Papp M, Vitalis Z, Altorjay I, et al. Acute phase proteins in the diagnosis and prediction of cirrhosis associated bacterial infections. Liver Int 2012;32:603-611.

38. Lazzarotto C, Ronsoni MF, Fayad L, et al. Acute phase proteins for the diagnosis of bacterial infection and prediction of mortality in acute complications of cirrhosis. Ann Hepatol 2013;12:599-607.

39. Dinic-Radovic V, Nagorni A, Brzacki V, Ristic L, Radovic M. Importance of certain pro-inflammatory indices in patients with liver cirrhosis and bacterial infection on prognosis and course of the disease. Med Arh 2012;66:19-23.

40. Ximenes RO, Farias AQ, Scalabrini Neto A, et al. Patients with cirrhosis in the ED: early predictors of infection and mortality. Am J Emerg Med 2016;34:25-29.

41. Kadam N, Acharya S, Shukla S, Gupta K. Ascitic fluid high sensitive C-reactive protein (hs-CRP). A prognostic marker in cirrhosis with spontaneous bacterial peritonitis. J Clin Diagn Res 2016;10:OC20-24.

42. Tsiakalos A, Karatzaferis A, Ziakas P, Hatzis G. Acute-phase proteins as indicators of bacterial infection in patients with cirrhosis. Liver Int 2009;29:1538-1542.

43. Connert S, Stremmel W, Elsing C. Procalcitonin is a valid marker of infection in decompensated cirrhosis. Z Gastroenterol 2003;41:165-170.

44. Lesińska M, Hartleb M, Gutkowski K, Nowakowska-Duława E. Procalcitonin and macrophage inflammatory protein- 1 beta (MIP$1 \beta)$ in serum and peritoneal fluid of patients with decompensated cirrhosis and spontaneous bacterial peritonitis. Adv Med Sci 2014;59:52-56.

45. Viallon A, Zeni F, Pouzet V, et al. Serum and ascitic procalcitonin levels in cirrhotic patients with spontaneous bacterial peritonitis: diagnostic value and relationship to pro-inflammatory cytokines. Intensive Care Med 2000;26:1082-1088.

46. Lin RS, Lee FY, Lee SD, et al. Endotoxemia in patients with chronic liver diseases: relationship to severity of liver diseases, presence of esophageal varices, and hyperdynamic circulation. J Hepatol 1995;22:165-172.

47. Bigatello LM, Broitman SA, Fattori L, et al. Endotoxemia, encephalopathy, and mortality in cirrhotic patients. Am J Gastroenterol 1987;82:11-15.

48. Opal SM. The clinical relevance of endotoxin in human sepsis: a critical analysis. J Endotoxin Res 2002;8:473-476.

49. Munford RS. Detoxifying endotoxin: time, place and person. J Endotoxin Res 2005;11:69-84.

50. Hanck C, Rossol S, Böcker U, Tokus M, Singer MV. Presence of plasma endotoxin is correlated with tumour necrosis factor receptor levels and disease activity in alcoholic cirrhosis. Alcohol Alcohol 1998;33:606-608.

51. Fukui H, Brauner B, Bode JC, Bode C. Plasma endotoxin concentrations in patients with alcoholic and non-alcoholic liver disease: reevaluation with an improved chromogenic assay. J Hepatol 1991;12:162-169.

52. Tobias PS, Soldau K, Gegner JA, Mintz D, Ulevitch RJ. Lipopolysaccharide binding protein-mediated complexation of lipopolysaccharide with soluble CD14. J Biol Chem 1995;270:10482-10488.

53. Frey EA, Miller DS, Jahr TG, et al. Soluble CD14 participates in the response of cells to lipopolysaccharide. J Exp Med 1992;176:1665-1671.

54. Pugin J, Schürer-Maly CC, Leturcq D, Moriarty A, Ulevitch RJ, Tobias PS. Lipopolysaccharide activation of human endothelial and epithelial cells is mediated by lipopolysaccharide-binding protein and soluble CD14. Proc Natl Acad Sci U S A 1993;90:2744-2748.

55. Finlay BB, Hancock RE. Can innate immunity be enhanced to treat microbial infections? Nat Rev Microbiol 2004;2:497-504.

56. Leventhal JS, Schröppel B. Toll-like receptors in transplantation: sensing and reacting to injury. Kidney Int 2012;81:826-832.

57. Paik YH, Schwabe RF, Bataller R, Russo MP, Jobin C, Brenner DA. Toll-like receptor 4 mediates inflammatory signaling by bacterial lipopolysaccharide in human hepatic stellate cells. Hepatology 2003;37:1043-1055.

58. Schumann RR, Leong SR, Flaggs GW, et al. Structure and function of lipopolysaccharide binding protein. Science 1990;249:1429-1431.

59. Albillos A, de la Hera A, González $M$, et al. Increased lipopolysaccharide binding protein in cirrhotic patients with marked immune and hemodynamic derangement. Hepatology 2003;37:208-217.

60. Albillos A, de-la-Hera A, Alvarez-Mon M. Serum lipopolysaccharide-binding protein prediction of severe bacterial infection in cirrhotic patients with ascites. Lancet 2004;363:1608-1610.

61. Agiasotelli D, Alexopoulou A, Vasilieva L, et al. High serum lipopolysaccharide binding protein is associated with increased mortality in patients with decompensated cirrhosis. Liver Int 2017;37:576-582.

62. Such J, Francés R, Muñoz C, et al. Detection and identification of bacterial DNA in patients with cirrhosis and culture-negative, nonneutrocytic ascites. Hepatology 2002;36:135-141.

63. Francés R, Zapater P, González-Navajas JM, et al. Bacterial DNA in patients with cirrhosis and noninfected ascites mimics the soluble immune response established in patients with spontaneous bacterial peritonitis. Hepatology 2008;47:978-985.

64. Caro E, Francés R, Zapater P, Pascual S, Bellot P, Such J. Grade of soluble inflammatory response is mainly affected by circulating bacterial DNA concentrations in cirrhosis. Liver Int 2016;36:1473-1480.

65. El-Naggar MM, Khalil - SA, El-Daker MA, Salama MF. Bacterial DNA and its consequences in patients with cirrhosis and culture-negative, non-neutrocytic ascites. J Med Microbiol 2008;57:1533-1538.

66. Sersté T, Bert F, Leflon-Guibout V, et al. Detection of bacterial DNA in serum and ascitic fluid of asymptomatic outpatients with cirrhosis and non-neutrocytic ascites. Liver Int 2011;31:494-498.

67. Mortensen C, Karlsen S, Grønbæk H, et al. No difference in portal and hepatic venous bacterial DNA in patients with cirrhosis undergoing transjugular intrahepatic portosystemic shunt insertion. Liver Int 2013;33:1309-1315.

68. Krohn S, Böhm S, Engelmann C, et al. Application of qualitative and quantitative real-time PCR, direct sequencing, and terminal restriction fragment length polymorphism analysis for detection and identification of polymicrobial 16S rRNA genes in ascites. J Clin Microbiol 2014;52:1754-1757.

69. Engelmann C, Krohn S, Prywerek D, et al. Detection of molecular bacterascites in decompensated cirrhosis defines a risk with decreased survival. Eur J Gastroenterol Hepatol 2016;28:1285-1292.

70. Appenrodt B, Lehmann LE, Thyssen L, et al. Is detection of bacterial DNA in ascitic fluid of clinical relevance? Eur J Gastroenterol Hepatol 2010;22:1487-1494.

71. Bruns T, Reuken PA, Stengel S, et al. The prognostic significance 
of bacterial DNA in patients with decompensated cirrhosis and suspected infection. Liver Int 2016;36:1133-1142.

72. Bruns T, Sachse S, Straube E, et al. Identification of bacterial DNA in neutrocytic and non-neutrocytic cirrhotic ascites by means of a multiplex polymerase chain reaction. Liver Int 2009;29:1206-1214.

73. Konikoff MR, Denson LA. Role of fecal calprotectin as a biomarker of intestinal inflammation in inflammatory bowel disease. Inflamm Bowel Dis 2006;12:524-534.

74. Vermeire S, Van Assche G, Rutgeerts P. Laboratory markers in IBD: useful, magic, or unnecessary toys? Gut 2006;55:426-431.

75. Sipponen T. Diagnostics and prognostics of inflammatory bowel disease with fecal neutrophil-derived biomarkers calprotectin and lactoferrin. Dig Dis 2013;31:336-344.

76. Burri E, Schulte F, Muser J, Meier R, Beglinger C. Measurement of calprotectin in ascitic fluid to identify elevated polymorphonuclear cell count. World J Gastroenterol 2013;19:2028-2036.

77. Lutz P, Pfarr K, Nischalke HD, et al. The ratio of calprotectin to total protein as a diagnostic and prognostic marker for spontaneous bacterial peritonitis in patients with liver cirrhosis and ascites. Clin Chem Lab Med 2015;53:2031-2039.

78. Homann C, Garred P, Graudal N, et al. Plasma calprotectin: a new prognostic marker of survival in alcohol-induced cirrhosis. Hepatology 1995;21:979-985.
79. Homann C, Christensen E, Schlichting P, Philipsen EK, Graudal NA, Garred P. Ascites fluid and plasma calprotectin concentrations in liver disease. Scand J Gastroenterol 2003;38:415-420.

80. Alempijević T, Štulić M, Popovic D, Culafic D, Dragasevic S, Milosavljevic T. The role of fecal calprotectin in assessment of hepatic encephalopathy in patients with liver cirrhosis. Acta Gastroenterol Belg 2014;77:302-305.

81. Gundling F, Schmidtler F, Hapfelmeier A, et al. Fecal calprotectin is a useful screening parameter for hepatic encephalopathy and spontaneous bacterial peritonitis in cirrhosis. Liver Int 2011;31:1406-1415.

82. Papp M, Sipeki N, Vitalis Z, et al. High prevalence of IgA class anti-neutrophil cytoplasmic antibodies (ANCA) is associated with increased risk of bacterial infection in patients with cirrhosis. J Hepatol 2013;59:457-466.

83. Guerra-Ruiz A, Casafont F, Cobo M, et al. Increased bactericidal/ permeability increasing protein in patients with cirrhosis. Liver Int 2010;30:94-101.

84. Kaltsa G, Bamias G, Siakavellas SI, et al. Systemic levels of human $\beta$-defensin 1 are elevated in patients with cirrhosis. Ann Gastroenterol 2016;29:63-70.

85. Castellano G, Stasi A, Intini A, et al. Endothelial dysfunction and renal fibrosis in endotoxemia-induced oliguric kidney injury: possible role of LPS-binding protein. Crit Care 2014;18:520. 